\title{
Towards closure of regional heat budgets in the North Atlantic using Argo floats and surface flux datasets
}

\author{
N. C. Wells, S. A. Josey, and R. E. Hadfield \\ National Oceanography Centre, European Way, Southampton, SO14 3ZH, UK \\ Received: 20 October 2008 - Published in Ocean Sci. Discuss.: 13 January 2009 \\ Revised: 2 April 2009 - Accepted: 3 April 2009 - Published: 22 April 2009
}

\begin{abstract}
The upper ocean heat budget $(0-300 \mathrm{~m})$ of the North Atlantic from $20^{\circ}-60^{\circ} \mathrm{N}$ is investigated using data from Argo profiling floats for 1999-2005 and the NCEP/NCAR and NOC surface flux datasets. Estimates of the different terms in the budget (heat storage, advection, diffusion and surface exchange) are obtained using the methodology developed by Hadfield et al. (2007a, b). The method includes optimal interpolation of the individual profiles to produce gridded fields with error estimates at a $10^{\circ} \times 10^{\circ}$ grid box resolution. Closure of the heat budget is obtained within the error estimates for some regions - particularly the eastern subtropical Atlantic - but not for those boxes that include the Gulf Stream. Over the whole range considered, closure is obtained for 13 (9) out of 20 boxes with the NOC (NCEP/NCAR) surface fluxes. The seasonal heat budget at $20-30^{\circ} \mathrm{N}, 35-25^{\circ} \mathrm{W}$ is considered in detail. Here, the NCEP based budget has an annual mean residual of $-55 \pm 35 \mathrm{Wm}^{-2}$ compared with a NOC based value of $-4 \pm 35 \mathrm{Wm}^{-2}$. For this box, the net heat divergence of $36 \mathrm{Wm}^{-2}\left(\right.$ Ekman $=-4 \mathrm{Wm}^{-2}$, geostrophic $=11 \mathrm{Wm}^{-2}$, diffusion $=29 \mathrm{Wm}^{-2}$ ) offsets the net heating of $32 \mathrm{Wm}^{-2}$ from the NOC surface heat fluxes. The results in this box are consistent with an earlier evaluation of the fluxes using measurements from research buoys in the subduction array which revealed biases in NCEP but good agreement of the buoy values with the NOC fields.
\end{abstract}

\section{Introduction}

Closure of the upper ocean heat budget has been a focus of many studies as it provides insights into the various processes controlling the temperature of the near surface layer and po-

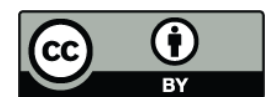

Correspondence to: N. C. Wells

(n.wells@noc.soton.ac.uk) tentially places an important constraint on the air-sea heat exchange. There have been a number of observational and modelling studies in the North Atlantic (Lamb and Bunker, 1982; Sarmiento, 1986; Böning and Herrmann, 1994; Jones and Leach, 1999; Wang and Carton, 2002; Stammer et al., 2004; and Dong and Kelly, 2004) to investigate the components of the North Atlantic heat budget. These studies indicate a primary balance between the net surface heat flux and local storage in the mid-latitude oceans on the monthly time scale. In addition, Dong and Kelly (2004) noted that the contribution of advection and diffusion to the tendency in mixed layer temperature can be significant spatially and temporally. Until recently, attempts to estimate the budget have been severely limited by lack of good quality and homogeneous data. However, with the advent of the global array of Argo profiling floats (Gould, 2005) profiles of temperature are now routinely available on a regular basis to a maximum depth of $2000 \mathrm{~m}$ over much of the global ocean.

In this paper we use the Argo data together with estimates of surface heat exchange from the NCEP/NCAR reanalysis (referred to as NCEP hereafter, Kalnay et al., 1996) and the NOC1.1 surface flux dataset (NOC hereafter, Josey et al., 1999) to investigate the upper ocean heat budget in various regions of the North Atlantic. Note that there are two versions of the NOC fields: the original NOC1.1 dataset and the subsequent NOC1.1a dataset which has been adjusted using inverse analysis with hydrographic heat transport constraints to close the global ocean heat budget (Grist and Josey, 2003). We have focused on the NOC1.1 version because it has been shown to provide good estimates of the surface heat exchange in the eastern North Atlantic following comparison with research buoy measurements (Josey et al., 1999). It is also known to have biases elsewhere and our hope is that the method developed in this paper may eventually be applied globally to obtain further insights into the spatial variation of these biases.

Published by Copernicus Publications on behalf of the European Geosciences Union. 
Gill and Niiler (1973) proposed and gave strong evidence for, the proposition that on a large scale (greater than $5^{\circ}$ latitude by $5^{\circ}$ longitude) the heat budget of the upper ocean is dominated by the local change in heat storage and surface heat fluxes, and that the advection and mixing terms are relatively small. However the North Atlantic circulation has an important role for the transport of heat In particular the meridional overturning circulation is a significant component of the heat budget on a basin scale. The northward heat flux at $26^{\circ} \mathrm{N}$ is about 1 petawatt (Bryden and Imawaki, 2001) which corresponds to a net annual heat flux from the ocean $\left(26^{\circ} \mathrm{N}\right.$ to $\left.70^{\circ} \mathrm{N}\right)$ to the atmosphere of $\sim 48 \mathrm{Wm}^{-2}$. This assumes that all the heat is released from the ocean between $26^{\circ} \mathrm{N}$ and $70^{\circ} \mathrm{N}$ and the surface area is $2.08 \times 10^{13} \mathrm{~m}^{2}$. This flux can be compared with monthly heat fluxes of up to $\pm 500 \mathrm{Wm}^{-2}$. Generally, although the advection and diffusion terms are smaller than the heat storage, they still make a significant contribution to the monthly heat budget.

Here we evaluate the total heat budget, including each of the terms noted above, for the North Atlantic using data from the Argo profiling floats which provide continuous coverage from 1999-2005. The winter atmospheric circulation over the North Atlantic Ocean is dominated by the North Atlantic Oscillation, which during this period was predominantly in the positive phase (increased westerly winds), in particular in 2000, 2002, 2004-2005. There were two significant negative events (decreased westerly winds), one in the latter part of 2003 and one in latter part of 2005. The associated interannual variations in surface heat flux are typically $\sim 20 \mathrm{Wm}^{-2}$, compared with a mean seasonal cycle typically $+/-200 \mathrm{Wm}^{-2}$ (Fig. 3), therefore the period 1999-2006 is a reasonable period for the study of the seasonal cycle in the North Atlantic Ocean. To check on the validity of our approach an earlier analysis based on the Ocean Circulation and Climate Advanced Model (OCCAM, Webb et al., 1998), has been used to determine the Argo sampling error in monthly mixed layer heat storage estimates (Hadfield et al., 2007a). Using OCCAM sub-sampled at the Argo positions, it was found that the mixed layer monthly heat storage, in the subtropical North Atlantic but not including the Gulf Stream, has a sampling error of $10-20 \mathrm{Wm}^{-2}$ when averaged over a $10^{\circ} \times 10^{\circ}$ area. This sampling error is sufficiently small to provide useful estimates of the heat budget over a significant fraction of the basin.

The paper is divided as follows: in Sect. 2 we discuss the method for estimation of the total heat budget. Details of the data required to make these estimates are given in Sect. 3. In Sect. 4, we present and discuss the main results of our analysis including individual terms, the total heat budget and error estimates. Finally, we draw some conclusions in Sect. 5.

\section{Heat budget method}

The heat budget for the upper ocean is given by:

$$
\begin{aligned}
& h \frac{\partial T_{a}}{\partial t}+h v_{a} \cdot \nabla T_{a}+\nabla \int_{-h}^{0} \hat{v} \hat{T} d z+\left(T_{a}-T_{h}\right)\left(w_{-h}\right) \\
& +h k_{x, y} \cdot \nabla^{2} T_{a}+k_{z} \frac{\partial^{2} T}{\partial z^{2}}=\frac{Q-Q_{-h}}{\rho C_{p}}
\end{aligned}
$$

where $T$ is potential temperature, $v$, horizontal velocity with $(u, v)$ the eastward and northward components, respectively, $w$, vertical velocity, $h$, depth of the upper ocean, $k_{x, y}, k_{z}$, horizontal and vertical diffusion coefficients, $\rho C_{p}$, specific heat capacity per unit volume (with $C_{p}$ and $\rho$ set to constants of $3986 \mathrm{~J} \mathrm{~kg}^{-1}{ }^{\circ} \mathrm{C}^{-1}$ and $1027 \mathrm{~kg} \mathrm{~m}^{-3}$, respectively), $Q$, net absorbed surface heat flux $\mathrm{Wm}^{-2}, Q_{-h}$, the penetrative solar radiation heat flux $\mathrm{Wm}^{-2}, \nabla \equiv(\partial / \partial x, \partial / \partial y)$ the horizontal gradient, $x, y$ and $z$ the eastward, northward and upward coordinates respectively and $t$, time. The subscripts $h$ and $a$ are used to indicate variables at depth $h$ and averaged between depth $h$ and the sea surface, respectively, $\hat{v}$ is the deviation from the vertically averaged velocity field $\left(v=v_{a}+\hat{v}\right)$ and $\hat{T}$ is the deviation from the vertically averaged temperature $\left(T=T_{a}+\hat{T}\right)$. This procedure is based on Stevenson and Niiler (1983) and adapted by Hadfield et al. (2007a).

The individual terms are: $h \frac{\partial T_{a}}{\partial t}$ is the local change in heat storage, $h v_{a} \cdot \nabla T_{a}$ is the horizontal advection of temperature, $\nabla \int_{-h}^{0} \hat{v} \hat{T} d z$ is the covariance of the horizontal velocity and temperature, $\left(T_{a}-T_{h}\right)\left(w_{-h}\right)$ is the vertical advection of temperature at depth $h, h k_{x, y} \cdot \nabla^{2} T_{a}$ is the horizontal diffusion of temperature, $k_{z} \frac{\partial^{2} T}{\partial z^{2}}$ is the vertical diffusion of temperature, $Q$ is the net downward heat flux at the sea surface and $Q_{-h}$, is the penetrative solar radiation at depth $h$. The two data sets used here for the net surface heat flux are the National Oceanography Centre air-sea fluxes determined by Josey et al. (1998) and the National Centre for Environmental Prediction /National Centre for Atmospheric Research (NCEP/NCAR) reanalysis (Kalnay et al., 1996, 2001).

The horizontal velocity $(u, v)$ is partitioned into two components: the monthly wind stress induced Ekman flow $\left(u_{e}\right.$ and $v_{e}$ ) and the geostrophic flow $\left(u_{g}\right.$ and $\left.v_{g}\right)$. The Ekman flow is given by:

$u_{e}=\frac{\tau_{y}^{0}}{\rho_{0} f h}$ and $v_{e}=-\frac{\tau_{x}^{0}}{\rho_{0} f h}$

where $\left(\tau_{x}^{0}, \tau_{y}^{0}\right)$ are components of wind stress, $\rho_{0}=$ sea water density, $h=$ mixed layer depth and $f=$ coriolis parameter.

The surface wind stress is obtained from the NOC and NCEP monthly mean wind stress values. Higher frequency contributions could make a contribution to the heat advection if there were associated high frequency variations in Ta. 
We believe these variations in Ta are only likely near frontal zones and mesoscale eddies which are not resolved in this study. These sub-grid scale processes are discussed below. The mixed layer depth is defined as the depth at which the temperature is $0.2^{\circ} \mathrm{C}$ below the surface temperature, and this definition allows capture of the spring re-stratification (Montegut et al., 2004). Argo floats only give reliable temperatures up to $10 \mathrm{~m}$ below the surface and therefore this is used as a surface temperature. The Ekman flow is assumed to be contained within the mixed layer. This may not always be the case, in particular, in the subtropical regions where Ekman flows can be deeper than the mixed layer and we make an estimate of this error (Sect. 4.3).

The geostrophic flow $\left(u_{g}\right.$ and $\left.v_{g}\right)$ is determined from the slope of sea level and a contribution from the density field within the upper ocean $(0-300 \mathrm{~m})$. Argo profiles are used to determine sea level height by the Bernoulli Inverse method (Cunningham, 2000; Alderson and Killworth, 2005). In the method the three properties conserved along streamlines are the compressible Bernoulli function, salinity and the modified potential temperature. This modified potential temperature is a linear combination of potential heat content and salinity. The Bernoulli Inverse method provides a best estimate of sea level height together with an error estimate for the period January 2003 to December 2005 only. For the earlier period (January 1999 to December 2002), sufficient salinity data was not available and therefore sea level height could not be determined. For this earlier period a temporal mean value from January 2003 to December 2005 is adopted. The baroclinic contribution to the geostrophic flow, was found to be small when compared with the barotropic contribution from the sea level slope.

The covariance of horizontal velocity and temperature $\left(\nabla \int_{-h}^{0} \hat{v} \hat{T} d z\right)$ is ignored in this study. Estimates suggest that it's contribution to the heat budget is much less than $5 \mathrm{Wm}^{2}$ (Hadfield et al., 2007b).

The vertical velocity has two components (i) Ekman pumping velocity calculated from the wind stress curl $w_{e}=\frac{\nabla \wedge \tau^{0}}{\rho_{o} \bar{f}}$ of the NCEP/NCAR and NOC data sets and (ii) the geostrophic convergence $\left(w_{g}=-\frac{\beta v_{g} h}{f}\right)$ associated with the change in Coriolis parameter with latitude, $\beta$. The vertical velocity $\mathrm{w}_{g}$ is calculated from the northward component of the geostrophic velocity, $v_{g}$, the depth $h$, and $f$ the Coriolis parameter.

The horizontal diffusion coefficient is assumed to be $5000 \mathrm{~m}^{2} \mathrm{~s}^{-1}$ in all boxes. This value was adopted by McCulloch and Leach (1998) in their heat budget analysis of the North Atlantic. The value represents the horizontal eddy diffusivity estimated from buoys drogued at $100 \mathrm{~m}$ (Schafer and Kraus, 1995). This value is larger than that estimated by Ledwell et al. (1993), based on the North Atlantic Tracer Release Experiment, who estimated values from 650 to $2300 \mathrm{~m}^{2} \mathrm{~s}^{-1}$ on scales from $300 \mathrm{~km}$ to $1000 \mathrm{~km}$. The value used represents the mixing associated with spatial and temporal scales below the resolution of the analysis (i.e. $10^{\circ} \times 10^{\circ}$ spatial resolution and 1 month time resolution). The vertical mixing coefficient has a value of $2.10^{-5} \mathrm{~m}^{2} \mathrm{~s}^{-1}$ (Ledwell et al., 1993) and represents vertical mixing within the upper layer on horizontal scales of hundreds of kilometers and time scales of months.

\section{Data and objective analysis method}

All the Argo profiles collected between 1 January 1999-31 December 2005 in the North Atlantic from $0^{\circ} \mathrm{N}$ and $70^{\circ} \mathrm{N}$ and $0^{\circ}-90^{\circ} \mathrm{W}$, and reaching a depth of at least $1000 \mathrm{~m}$ are used in this study. There were 49599 floats of which 43127 floats $(86 \%)$ were used for analysis. The data quality procedures are discussed by Hadfield et al. (2007a, b).

Argo floats are designed to sample an ocean area of $3^{\circ} \times 3^{\circ}$ resolution at a frequency of 10 days, however, the ARGO array was significantly lower than this resolution for large parts of the North Atlantic, particularly during the early years of ARGO. This means that our choice of box size for the heat budget has to reflect this resolution for there to be sufficient samples. With the use of an eddy permitting ocean model (OCCAM) we have found (see Hadfield et al., 2007a) that a monthly time scale and a horizontal resolution of $10^{\circ} \times 10^{\circ}$ boxes, is sufficient to obtain good estimates of the terms in Eq. (1).

We adopted an objective analysis method (Gandin, 1963; Bretherton et al., 1976; Böhme and Send, 2005; Hadfield et al., 2007a) to obtain the best linear estimate of temperature at a given horizontal position and given vertical level. The method is discussed fully by Hadfield et al. (2007a) and here we will outline the basis of the method. In this study the covariance of the data is assumed to be Gaussian, with a decay scale determined by four correlation parameters: a longitudinal scale $(L x)$, a latitudinal scale $(L y)$, a cross-isobath scale $(\Phi)$, and a temporal scale $(\Delta t)$. The objective estimate of the potential temperature at a grid point $T_{\text {grid }}$, for each 10 decibar level, is given by:

$$
T_{\text {grid }}=T_{\mathrm{WOA}}+\sum_{i=1}^{N} w_{i}\left(T_{i}-T_{\mathrm{WOA}}\right)
$$

$T_{i}$ denotes the " $N$ " profiles closest in space and time to the grid point being interpolated to. It was found that beyond $N=40$ there was little discernible difference to the interpolated value, and therefore we set $N=40$ for this analysis.

$T_{\mathrm{WOA}}$ is the monthly mean field from the World Ocean Atlas (WOA) (Stephens et al., 2001) climatology. The weighting matrix $\mathrm{w}$ is given by $w=\mathrm{Cdg} \mathrm{Cdd}^{-1}$ where $\mathrm{Cdg}$ is the covariance matrix between the analysed value at the observation point and the grid point value or the data-grid covariance. $\mathrm{Cdd}^{-1}$ is the inverted covariance matrix between observation points or the data-data covariance. 
Given a very large number of observations randomly distributed over the North Atlantic we could evaluate Cdd directly. However, this is not the case, and we choose the following Gaussian model function to describe the covariance functions (Böhme and Send, 2005). The data-grid covariance is:

$\mathrm{Cdg}_{i}=\left\langle s^{2}\right\rangle \cdot \exp \left\{-\left[\frac{D x_{i, g}^{2}}{L x^{2}}+\frac{D y_{i, g}^{2}}{L y^{2}}+\frac{F_{i, g}^{2}}{\Phi^{2}}+\frac{D t_{i, g}^{2}}{\Delta t^{2}}\right]\right\}$

The data-data covariance is:

$\operatorname{Cdd}_{i}=\left\langle s^{2}\right\rangle \cdot \exp \left\{-\left[\frac{D x_{i, j}^{2}}{L x^{2}}+\frac{D y_{i, j}^{2}}{L y^{2}}+\frac{F_{i, j}^{2}}{\Phi^{2}}+\frac{D t_{i, j}^{2}}{\Delta t^{2}}\right]\right\}$

$D x$ and $D y$ are the spatial distances between the floats and the grid point in the zonal and meridional directions respectively, and $D t$ is temporal separation between the float and grid point. $F$, the cross isobath separation, is calculated from the following formula,

$F=\frac{|P V(a)-P V(b)|}{\sqrt{P V^{2}(a)+P V^{2}(b)}}$

where $P V$ is the barotropic potential vorticity, $f / H, f$ is the Coriolis parameter and $H$ is the full ocean depth. The inclusion of the cross-isobath separation considers the tendency of ocean currents to follow the bathymetry. The subscripts refer to the grid point $(g)$, the observation point $(i)$ and another observation point $(j) . s^{2}$ is the signal variance defined $s^{2}=\frac{1}{N} \sum\left(T_{i}-T_{\text {WOA }}\right)^{2}$ where $T_{i}$ is the float temperature and $T_{\text {WOA }}$ is the climatogical temperature or the first guess field for optimal interpolation. $N$ is the number of closest floats and here $N=40$.

The chosen values for $L x, L y, \Phi$, and $\Delta t$, depend on the availability of observations. If there are too few observations then the interpolation will be strongly weighted to the climatology, whilst if there are too many observations there will be over-smoothing of the data. We choose a length scale of $500 \mathrm{~km}$, time scale of 30 days and $\Phi=0.25$ at the surface. The horizontal scale decreases linearly to $250 \mathrm{~km}$ at $500 \mathrm{~m}$ depth and the time scale increases linearly to 90 days. Below this the values remain constant.

The Argo temperature data were optimally interpolated onto monthly $2^{\circ} \times 2^{\circ}$ bins, over an area from $9.5^{\circ} \mathrm{N}$ to $69.5^{\circ} \mathrm{N}$ and from $0.5^{\circ} \mathrm{W}$ to $84.5^{\circ} \mathrm{W}$., using the 40 closest Argo profiles to each grid point and the WOA (2001) climatology (Stephens et al., 2001) as the first guess field. By this method values of potential temperature were interpolated onto 104 horizontal surfaces (from $10 \mathrm{~m}, 15 \mathrm{~m}$ to $200 \mathrm{~m}$, $210 \mathrm{~m}$ to $500 \mathrm{~m}, 520 \mathrm{~m}$ to $1000 \mathrm{~m}, 1050 \mathrm{~m}$ to $150 \mathrm{~m}$ ). The values were interpolated to the centre point of each calendar month from February 1999 to December 2005. The heat budget has been calculated using a fixed depth of $300 \mathrm{~m}$, to calculate heat storage. The monthly interpolated fields were then averaged into $10^{\circ} \times 10^{\circ}$ bins for the heat budget analysis and a 3 monthly running mean was applied. The region north of $60^{\circ} \mathrm{N}$ and south of $20^{\circ} \mathrm{N}$ is not considered in this study because of large amount of land and ice at higher latitudes and the more irregular seasonal in heat storage at low latitudes. These spatial and temporal scales were chosen in view of a model based analysis of error estimates in the heat budget terms; these scales represent the minimum scales which could be reliably resolved over large areas of the North Atlantic and for the majority of the study period (Hadfield et al., 2007a). Studies of the heat budget from 2006 onwards and in higher sampled regions of the North Atlantic may be possible at a higher resolution.

The 7 year mean seasonal cycle of the mixed layer depth (Fig. 1), shows that to the south of $50^{\circ} \mathrm{N}$ the maximum depth is less than $200 \mathrm{~m}$ at $10^{\circ} \times 10^{\circ}$ resolution. At the higher resolution $2^{\circ} \times 2^{\circ}$ the maximum mixed layer can exceed depths of $300 \mathrm{~m}$ locally near the Gulf Stream. In the northern most boxes $\left(50-60^{\circ} \mathrm{N}\right)$ the deepest mixed layers approach $300 \mathrm{~m}$ at this resolution. At higher resolution $2^{\circ} \times 2^{\circ}$, mixed layers can approach $500 \mathrm{~m}$ depth in the Labrador Sea, Irminger Sea and Greenland Sea, however at this resolution there are insufficient ARGO floats to provide a good estimate of the heat storage. The maximum mixed layer depth when averaged over a $10^{\circ} \times 10^{\circ}$ boxes, will therefore be smaller than a pointwise estimate of the mixed layer depth. Similarly, a monthly average will miss high frequency events. Furthermore, as the depth of the chosen layer is increased, signals from the ocean interior tend to dominate over those in the upper ocean. The chosen depth of $300 \mathrm{~m}$ is therefore a compromise between the Argo sampling and the need to sample the upper ocean adequately at a $10^{\circ} \times 10^{\circ}$ resolution.

The mean seasonal cycle of the depth averaged temperature $(0-300 \mathrm{~m}) T_{a}$ and the temperature at $300 \mathrm{~m}$ is shown in Fig. 2. $T_{a}$ shows a seasonal cycle of about $1^{\circ} \mathrm{C}$, whilst $T_{-h}$ shows little seasonal variation. In the lowest latitudes ( $T_{-h}$ is significantly below $T_{a}$, because of the shallower mixed layer depths at these latitudes (Fig. 1). In the most northern boxes $T_{a}$ is close to $T_{-h}$ in late winter, at the time of the deepest mixed layers.

\section{Results}

\subsection{NCEP and NOC net heat flux fields}

We first compare the NCEP and NOC net heat flux fields for the period January 1999 to December 2005. Annual mean values averaged onto $10^{\circ} \times 10^{\circ}$ boxes are listed in Table 1 and the seasonal cycle for each box is shown in Fig. 3. The NCEP fields have greater heat loss (or weaker heat gain in summer) than NOC and this is consistent with previous studies which have found strong net heat loss values in the NCEP fields arising from the latent and sensible heat flux terms (Josey, 2001; Renfrew, 2002). In the annual mean, the differences are largest towards the western boundary at $30^{\circ}-40^{\circ} \mathrm{N}$ with 


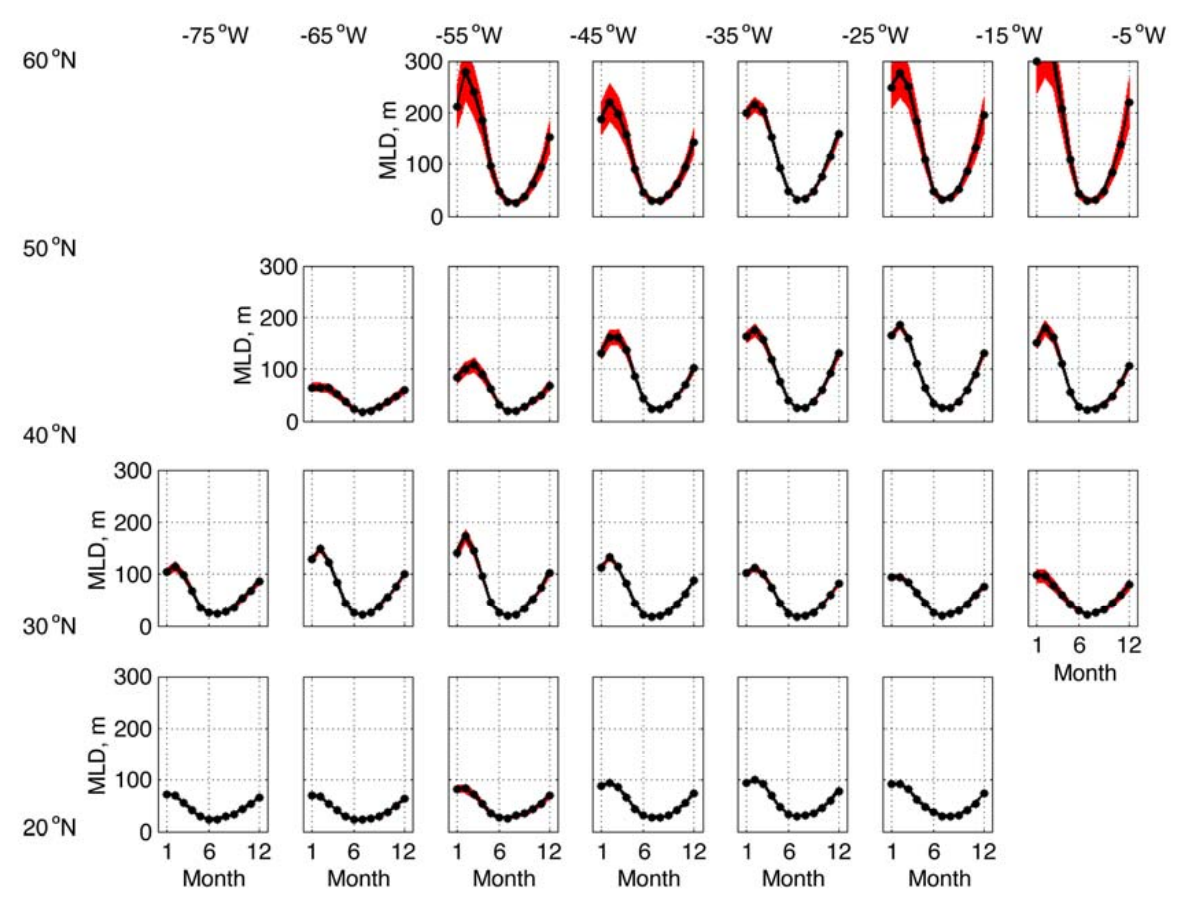

Fig. 1. Seasonal cycle in Mixed Layer Depth (m) for different $10^{\circ} \times 10^{\circ}$ boxes throughout the North Atlantic. The red shading indicates the estimated error.

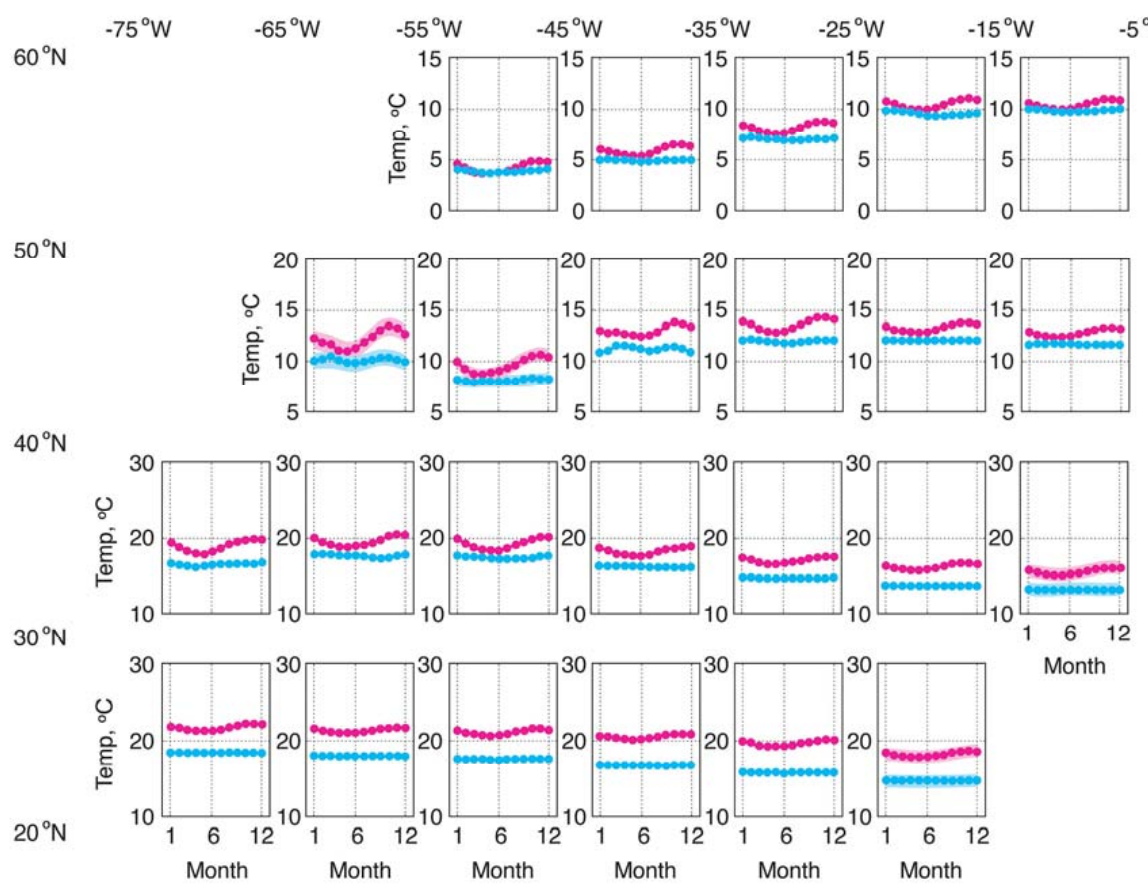

Fig. 2. Seasonal cycle in $T_{a}$ over the upper $300 \mathrm{~m}$ (magenta) and $T_{-300 \mathrm{~m}}$ (cyan) for different $10^{\circ} \times 10^{\circ}$ boxes in the North Atlantic. The shading indicates the errors associated with estimating the temperature variables from the Argo dataset. 
Table 1. Annual mean net heat flux for (a) NCEP and NOC, with the latter shown in brackets and (b) the RMS difference between the two flux fields. Positive values indicate heat flux into the ocean.

\begin{tabular}{lrrrrrrr}
\hline a) & $75-65^{\circ} \mathrm{W}$ & $65-55^{\circ} \mathrm{W}$ & $55-45^{\circ} \mathrm{W}$ & $45-35^{\circ} \mathrm{W}$ & $35-25^{\circ} \mathrm{W}$ & $25-15^{\circ} \mathrm{W}$ & $15-5^{\circ} \mathrm{W}$ \\
\hline $50-60^{\circ} \mathrm{N}$ & - & - & $-19(-10)$ & $-27(-27)$ & $-33(-23)$ & $-50(-29)$ & $-36(-18)$ \\
$40-50^{\circ} \mathrm{N}$ & - & $-20(-12)$ & $-7(6)$ & $-84(-54)$ & $-29(-15)$ & $-11(0)$ & $-5(11)$ \\
$30-40^{\circ} \mathrm{N}$ & $-113(-73)$ & $-104(-57)$ & $-56(-14)$ & $-21(12)$ & $-1(23)$ & $-2(13)$ & $3(30)$ \\
$20-30^{\circ} \mathrm{N}$ & $-23(22)$ & $-19(29)$ & $-13(35)$ & $-10(39)$ & $-16(36)$ & $12(42)$ & - \\
\hline $\mathrm{b})$ & $75-65^{\circ} \mathrm{W}$ & $65-55^{\circ} \mathrm{W}$ & $55-45^{\circ} \mathrm{W}$ & $45-35^{\circ} \mathrm{W}$ & $35-25^{\circ} \mathrm{W}$ & $25-15^{\circ} \mathrm{W}$ & $15-5^{\circ} \mathrm{W}$ \\
\hline $50-60^{\circ} \mathrm{N}$ & - & - & 23 & 19 & 26 & 30 & 27 \\
$40-50^{\circ} \mathrm{N}$ & - & 14 & 24 & 35 & 8 & 14 & 18 \\
$30-40^{\circ} \mathrm{N}$ & 43 & 48 & 43 & 34 & 25 & 17 & 29 \\
$20-30^{\circ} \mathrm{N}$ & 45 & 49 & 48 & 50 & 52 & 29 & - \\
\hline
\end{tabular}

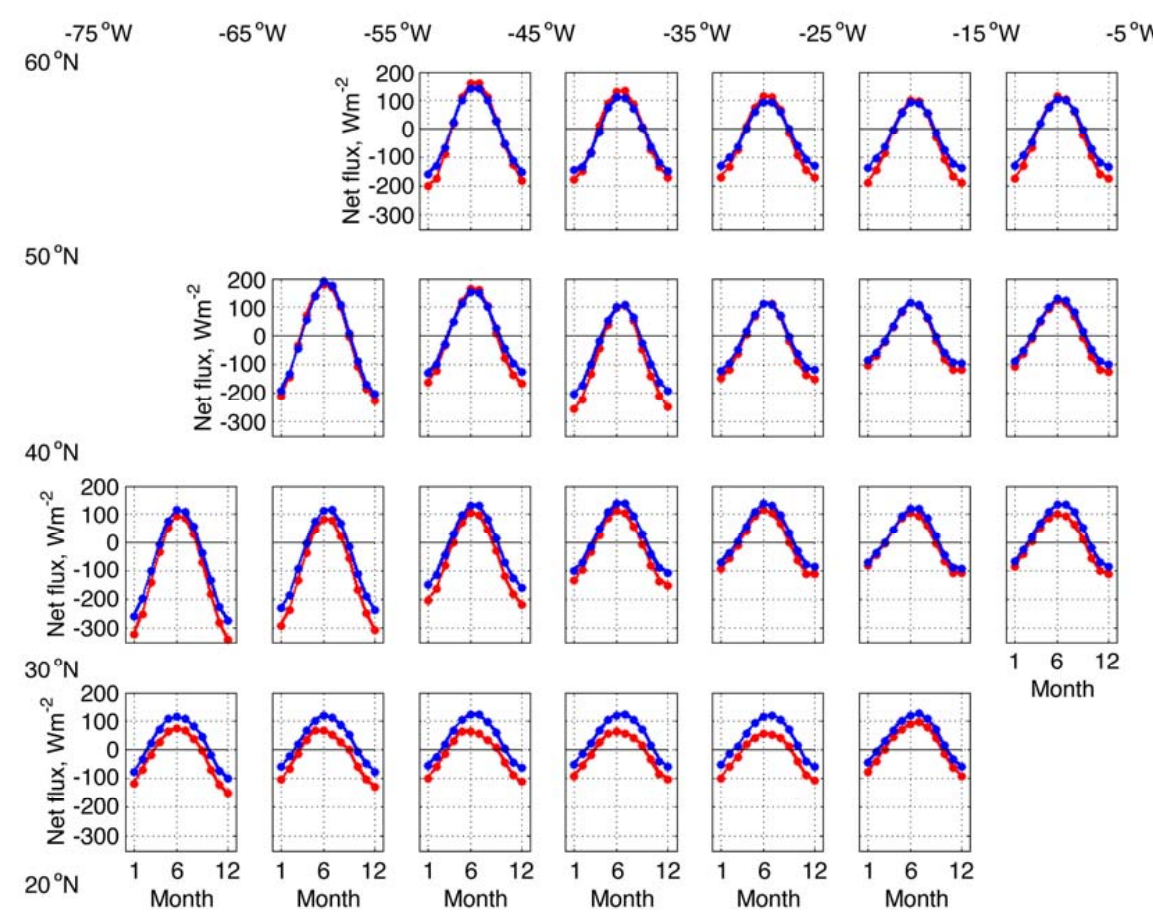

Fig. 3. Seasonal cycle in absorbed net flux for NCEP (red) and NOC (blue) derived using monthly averages between 1999 and 2005 , values in $\mathrm{Wm}^{-2}$.

the NCEP net heat loss exceeding NOC by up to $47 \mathrm{Wm}^{-2}$. Closer agreement is found elsewhere, with the lowest RMS differences $\left(<20 \mathrm{Wm}^{-2}\right)$ in the eastern basin at $40^{\circ}-50^{\circ} \mathrm{N}$.

There are a number of potential reasons for the differences between the NOC and NCEP/NCAR flux fields, the two main ones being: 1) variations in the parameterizations used to estimate the fluxes, with the NCEP fields known to have latent and sensible heat loss which is unrealistically strong at high latitudes (Renfrew et al., 2002); 2) sampling issues (i.e. major reduction in the number of observations towards high latitudes, which is most severe in winter months) which have a direct impact on the purely observation based NOC fields and an indirect effect on the NCEP fields as these same observations are assimilated into the atmospheric model used for the reanalysis. In this context, we note that Gulev et al. (2007) argued that sampling errors may be up to $60-80 \mathrm{Wm}^{-2}$ in the subpolar North Atlantic and that these biases may have a systematic nature in some regions.

Given the RMS results we expect a close correspondence between the NOC and NCEP seasonal cycles of net heat flux in the eastern basin at $40^{\circ}-50^{\circ} \mathrm{N}$ and this is found to be the case (Fig. 3). Further south, an offset is introduced between 
Table 2. Annual mean values of fixed depth heat storage with error estimates, $\mathrm{Wm}^{-2}$.

\begin{tabular}{rrrrrrrr}
\hline & $75-65^{\circ} \mathrm{W}$ & $65-55^{\circ} \mathrm{W}$ & $55-45^{\circ} \mathrm{W}$ & $45-35^{\circ} \mathrm{W}$ & $35-25^{\circ} \mathrm{W}$ & $25-15^{\circ} \mathrm{W}$ & $15-5^{\circ} \mathrm{W}$ \\
\hline $50-60^{\circ} \mathrm{N}$ & - & - & $3 \pm 17$ & $2 \pm 41$ & $5 \pm 34$ & $2 \pm 16$ & $0 \pm 20$ \\
$40-50^{\circ} \mathrm{N}$ & - & $-18 \pm 117$ & $-5 \pm 104$ & $-1 \pm 38$ & $8 \pm 24$ & $0 \pm 9$ & $0 \pm 18$ \\
$30-40^{\circ} \mathrm{N}$ & $1 \pm 44$ & $-6 \pm 17$ & $1 \pm 19$ & $2 \pm 6$ & $1 \pm 7$ & $1 \pm 7$ & $0 \pm 53$ \\
$20-30^{\circ} \mathrm{N}$ & $0 \pm 16$ & $0 \pm 19$ & $3 \pm 26$ & $1 \pm 9$ & $3 \pm 18$ & $-1 \pm 30$ & - \\
\hline
\end{tabular}

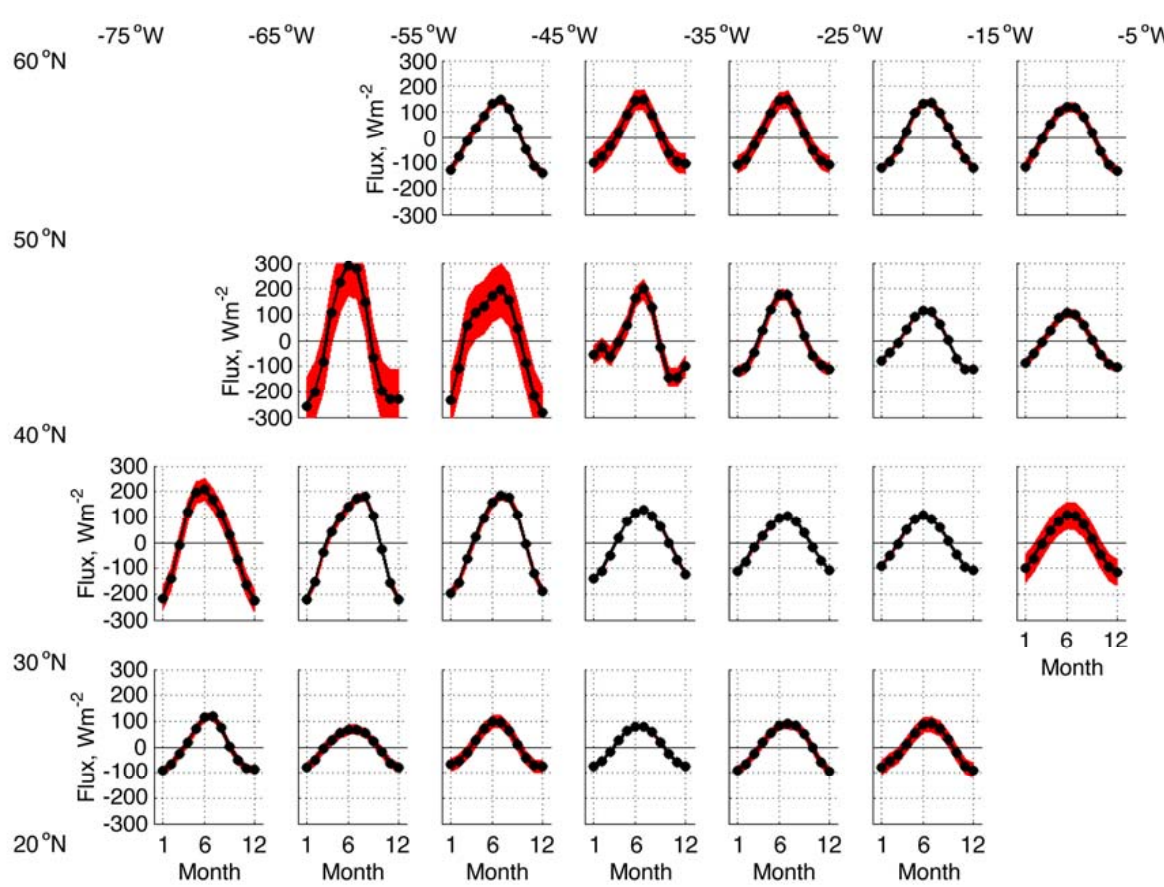

Fig. 4. Seasonal cycle in the heat storage of the upper $300 \mathrm{~m}\left(\mathrm{Wm}^{-2}\right)$ for different $10^{\circ} \times 10^{\circ}$ boxes in the North Atlantic. Red shading indicates the estimated error.

the two seasonal cycles with NCEP persistently lower than NOC in the range $20^{\circ}-30^{\circ} \mathrm{N}$. Note that in the eastern part of this range the NOC net heat flux has previously been shown to be in good agreement with high quality measurements from WHOI flux buoys deployed as part of a subduction study (Josey, 2001). Finally, note that the largest differences between NCEP and NOC in the annual mean towards the western boundary at $30^{\circ}-40^{\circ} \mathrm{N}$, commented on above, are primarily the result of stronger NCEP heat loss in the winter months.

\subsection{Heat storage}

Annual mean heat storage values have been determined for the full period 1999-2005 (Table 2) and these indicate that the heat storage change is not significantly different from zero within the error of the estimate for all boxes. This is to be expected if there is no significant change in temperature over this period. Note that the heat storage errors are smallest in the eastern and central subtropical gyre $\left(30^{\circ}-40^{\circ} \mathrm{N}\right.$, $\left.15^{\circ}-45^{\circ} \mathrm{W}\right)$, and greatest in the Gulf stream extension region $\left(40^{\circ}-50^{\circ} \mathrm{N}, 45^{\circ}-65^{\circ} \mathrm{W}\right)$.

The monthly change in heat storage, $\rho C_{p} h \frac{\partial T_{a}}{\partial t}$ from Eq. (1), is shown in Fig. 4 with estimated errors for each of the $10^{\circ} \times 10^{\circ}$ boxes. The errors exceed $100 \mathrm{Wm}^{-2}$ in the Gulf Stream $\left(40^{\circ}-50^{\circ} \mathrm{N}, 45^{\circ}-65^{\circ} \mathrm{W}\right)$, but decrease markedly away from this region. The maximum rate of change is generally associated with the winter and summer solstice in December and June, except for the region $\left(30^{\circ}-40^{\circ} \mathrm{N}, 45^{\circ}-\right.$ $65^{\circ} \mathrm{W}$ ) where the maximum is delayed by one month. The zero change in heat storage occurs in March when the minimum heat storage is found, and September when the maximum heat storage occurs. 
Table 3. Annual mean wind-driven heat convergence for individual $10^{\circ} \times 10^{\circ}$ boxes in the North Atlantic based on the NCEP reanalysis wind stress and the NOC climatology wind stress, with the latter given in brackets. Values are in $\mathrm{Wm}^{-2}$.

\begin{tabular}{rrrrrrrr}
\hline & $75-65^{\circ} \mathrm{W}$ & $65-55^{\circ} \mathrm{W}$ & $55-45^{\circ} \mathrm{W}$ & $45-35^{\circ} \mathrm{W}$ & $35-25^{\circ} \mathrm{W}$ & $25-15^{\circ} \mathrm{W}$ & $15-5^{\circ} \mathrm{W}$ \\
\hline $50-60^{\circ} \mathrm{N}$ & - & - & $1(1)$ & $12(9)$ & $15(11)$ & $9(8)$ & $3(4)$ \\
$40-50^{\circ} \mathrm{N}$ & - & - & $28(29)$ & $28(26)$ & $16(13)$ & $9(8)$ & $4(4)$ \\
$30-40^{\circ} \mathrm{N}$ & $3(4)$ & $5(7)$ & $4(6)$ & $3(4)$ & $2(2)$ & $2(2)$ & $1(0)$ \\
$20-30^{\circ} \mathrm{N}$ & $-6(-8)$ & $-6(-7)$ & $-6(-7)$ & $-5(-5)$ & $-4(-4)$ & $3(4)$ & - \\
\hline
\end{tabular}

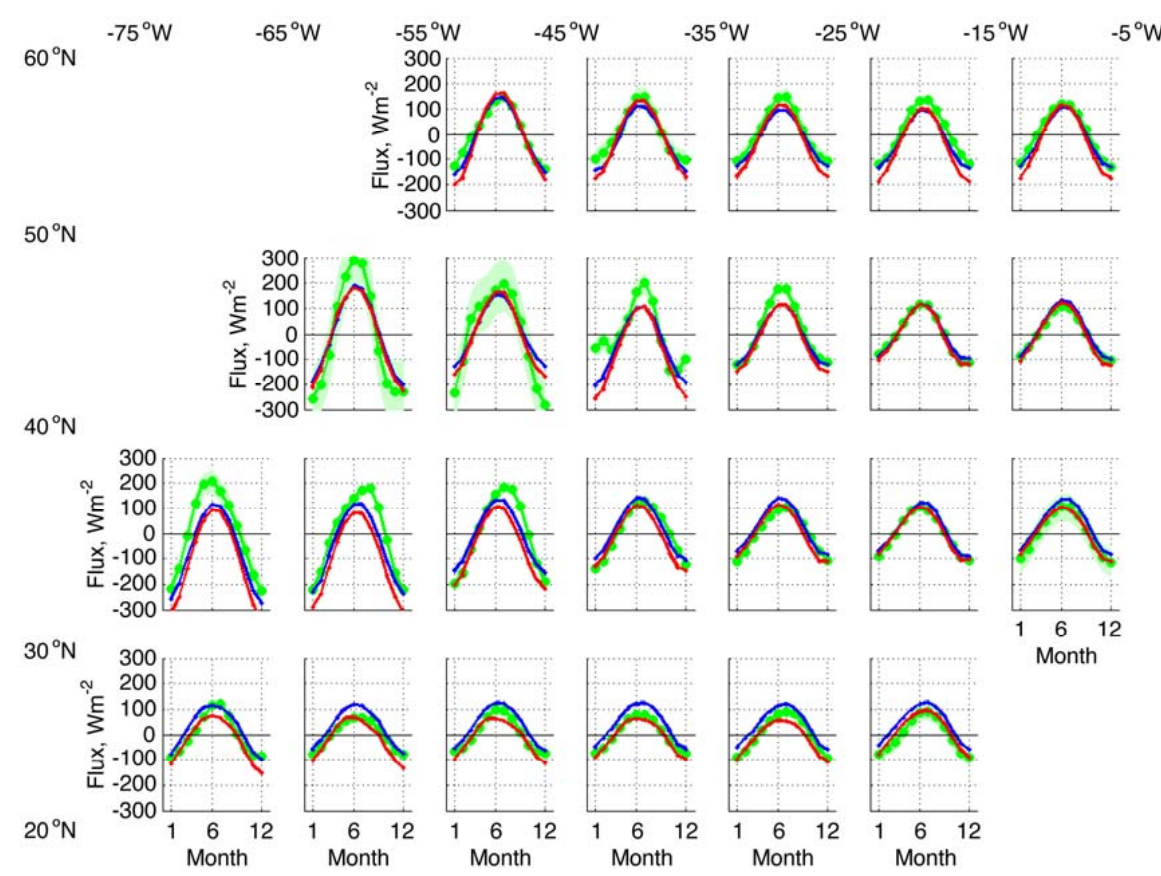

Fig. 5. Seasonal cycle in heat storage (green), absorbed net flux for NCEP (red) and NOC (blue) derived using monthly averages between 1999 and 2005, values in $\mathrm{Wm}^{-2}$.

The error ranges shown on the figure are due to spatial and temporal undersampling and have been determined by sub-sampling the OCCAM model using the temporal and spatial positions of the ARGO floats. The RMS differences between the fully sampled model heat storage and the subsampled heat storage provided an estimate of the sampling error. Note that instrument errors have been largely removed by a range of quality control procedures (see Hadfield et al., 2007a). The errors sampling are largest at $40^{\circ}-50^{\circ} \mathrm{N}$, west of $45^{\circ} \mathrm{W}$ in the region of the Gulf Stream extension. They are also large in the upwelling region off the NW African Coast $\left(30^{\circ}-40^{\circ} \mathrm{N}, 5^{\circ}-15^{\circ} \mathrm{W}\right)$. The large values for the errors are associated with the high spatial gradients and temporal variability in these regions where major contributions by advection and diffusion are expected.
The mean monthly change in heat storage is compared with the NCEP and NOC fluxes in Fig. 5. Good correspondence with both NCEP and NOC fluxes is found in many of the southern and eastern regions of the North Atlantic. In particular, for all 6 of the $20^{\circ}-30^{\circ}$ boxes, four of the $30^{\circ}-$ $40^{\circ}$ boxes, and 2 of the $40^{\circ}-50^{\circ}$ boxes, the heat storage estimates are close to or within the estimates of the two surface heat flux datasets. The boxes west of $45^{\circ} \mathrm{W}$ between $30^{\circ}$ and $40^{\circ} \mathrm{N}$, and west of $25^{\circ} \mathrm{W}$ between $40^{\circ}$ and $50^{\circ} \mathrm{N}$, which contain the Gulf Stream extension and the North Atlantic Current, have much larger seasonal heat storage cycles than can be accounted for by surface heat flux variations alone. The enhancement of the heat storage is probably related to advection and mixing processes within the ocean and this is discussed in Sect. 4.3. 
Table 4. Annual mean geostrophic heat convergence for individual $10^{\circ} \times 10^{\circ}$ boxes in the North Atlantic, $\mathrm{Wm}^{-2}$. Negative values indicate a warming contribution.

\begin{tabular}{lrrrrrrr}
\hline & $75-65^{\circ} \mathrm{W}$ & $65-55^{\circ} \mathrm{W}$ & $55-45^{\circ} \mathrm{W}$ & $45-35^{\circ} \mathrm{W}$ & $35-25^{\circ} \mathrm{W}$ & $25-15^{\circ} \mathrm{W}$ & $15-5^{\circ} \mathrm{W}$ \\
\hline $50-60^{\circ} \mathrm{N}$ & - & - & $3 \pm 2$ & $22 \pm 10$ & $-8 \pm 9$ & $42 \pm 7$ & - \\
$40-50^{\circ} \mathrm{N}$ & - & - & $-161 \pm 41$ & $3 \pm 16$ & $-24 \pm 6$ & $-21 \pm 2$ & $-10 \pm 2$ \\
$30-40^{\circ} \mathrm{N}$ & $60 \pm 16$ & $-9 \pm 4$ & $-6 \pm 3$ & $2 \pm 3$ & $0 \pm 2$ & $6 \pm 2$ & - \\
$20-30^{\circ} \mathrm{N}$ & $13 \pm 2$ & $-9 \pm 2$ & $8 \pm 2$ & $27 \pm 4$ & $11 \pm 4$ & $5 \pm 6$ & - \\
\hline
\end{tabular}

Table 5. The mean diffusive heat convergence for $10^{\circ} \times 10^{\circ}$ boxes in the North Atlantic.

\begin{tabular}{lrrrrrrr}
\hline & $75-65^{\circ} \mathrm{W}$ & $65-55^{\circ} \mathrm{W}$ & $55-45^{\circ} \mathrm{W}$ & $45-35^{\circ} \mathrm{W}$ & $35-25^{\circ} \mathrm{W}$ & $25-15^{\circ} \mathrm{W}$ & $15-5^{\circ} \mathrm{W}$ \\
\hline $50-60^{\circ} \mathrm{N}$ & - & - & -55 & -24 & -16 & 27 & 47 \\
$40-50^{\circ} \mathrm{N}$ & - & 19 & -76 & 34 & 17 & 5 & -3 \\
$30-40^{\circ} \mathrm{N}$ & - & 29 & 35 & 22 & 4 & 4 & 4 \\
$20-30^{\circ} \mathrm{N}$ & 10 & 9 & 15 & 21 & 29 & 22 & - \\
\hline
\end{tabular}
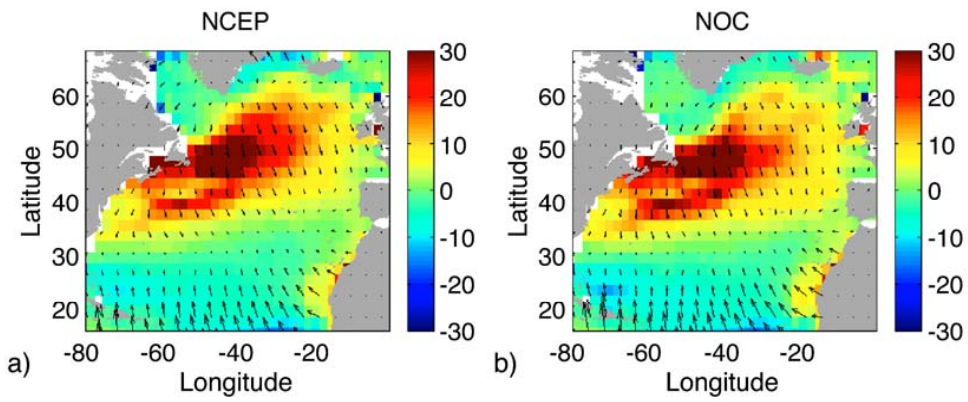

Fig. 6. The mean horizontal Ekman heat divergence calculated using (a) the NCEP wind stress field and (b) the NOC wind stress (Wm ${ }^{-2}$ ). Vectors indicate the direction of Ekman volume flux.

\subsection{Heat advection and diffusion}

In order to understand the relationship between the heat storage and the surface fluxes it is necessary to consider all the terms in the heat budget from 0-300 $\mathrm{m}$ described in Eq. (1) and we now consider the contributions due to advection and diffusion. The annual mean Ekman contribution to the horizontal heat divergence is shown in Fig. 6 and Table 3 for NCEP and NOC wind stress values respectively, together with error estimates. Both the NCEP and NOC wind stress estimates and heat divergences are very similar on this scale. Positive values of heat divergence (cooling) occur between $30^{\circ} \mathrm{N}$ and $60^{\circ} \mathrm{N}$, with large values of up to $28 \mathrm{Wm}^{-2}$ at about $50^{\circ} \mathrm{N}$ close to the position of the Gulf Stream extension and the North Atlantic current. This region is associated with enhanced westerly wind stress and large horizontal temperature gradients. Heat convergence (warming) is generally confined to lower latitudes below $20^{\circ} \mathrm{N}$. This is associated with the easterly trade winds enhancing the Ekman flux towards the centre of the subtropical gyre, and hence exporting heat into this region. The exception to this is the upwelling area off North Africa, where heat divergence is found. There is a strong seasonal variation in the Ekman contribution (Fig. 7) with largest values during the winter period up to $\sim 50 \mathrm{Wm}^{-2}$ east of Newfoundland $\left(45^{\circ}-55^{\circ} \mathrm{W}, 40^{\circ}-50^{\circ} \mathrm{N}\right.$ box $)$. Estimates of error associated with the penetration of the Ekman layer below the mixed layer are -4 to $7 \mathrm{Wm}^{-2}$ with an average RMS error of $0.9 \mathrm{Wm}^{2}$.

The geostrophic heat divergence (Table 4) has values ranging from zero to more than $150 \mathrm{Wm}^{-2}$ east of Newfoundland and with a standard deviation of $40 \mathrm{Wm}^{-2}$. The errors for the geostrophic divergence come mainly from the estimate of the sea level pressure gradient obtained from the Bernoulli method and the Argo hydrographic profiles. There is little seasonal signal in the geostrophic heat divergence, despite the seasonal variability in wind stress and Ekman transport.

The final contribution to the heat budget comes from the diffusion terms. Table 5 and Fig. 8 show the annual 


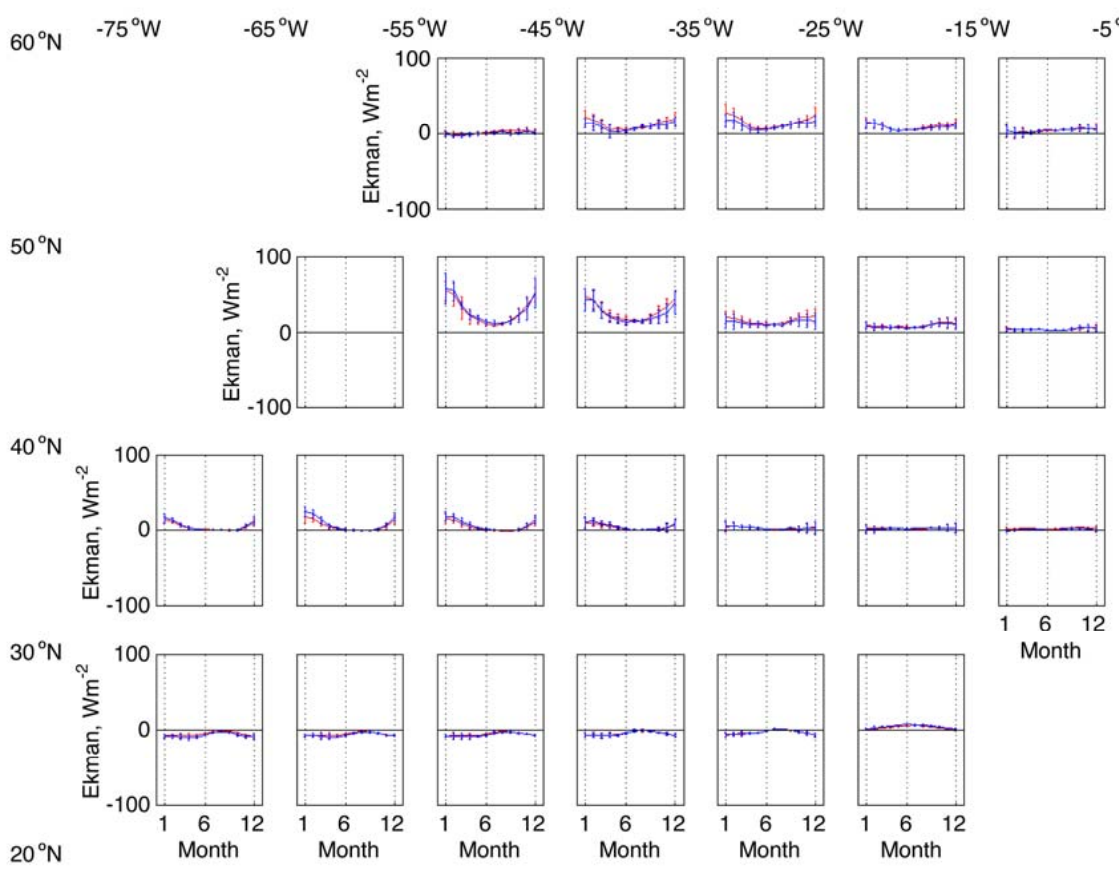

Fig. 7. Seasonal cycle in the horizontal Ekman heat convergence for different $10^{\circ} \times 10^{\circ}$ boxes in the North Atlantic. Fluxes based on the NCEP (red) and NOC (blue) wind stress fields are shown. The error bars indicate two standard errors of the seasonal values used to obtain the seasonal mean.

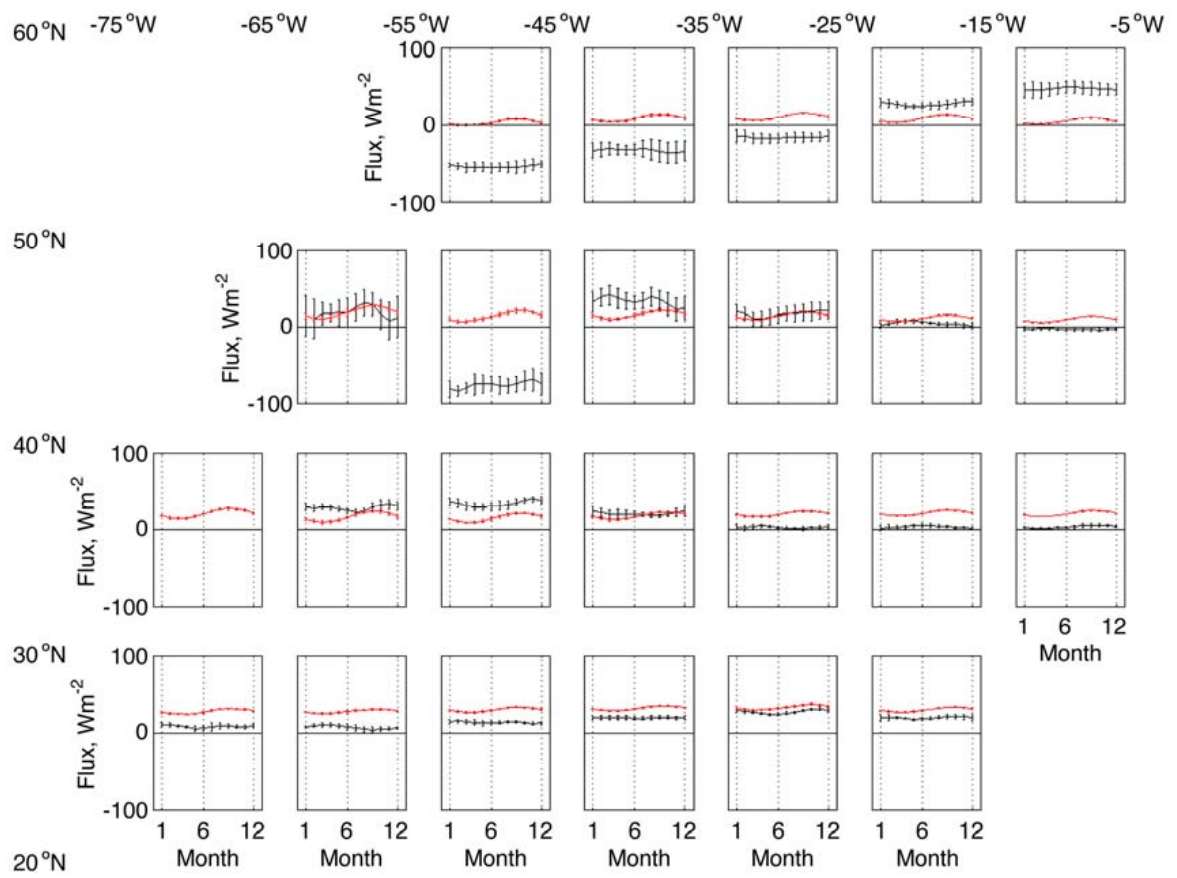

Fig. 8. Seasonal cycle in the diffusive heat flux for different $10^{\circ} \times 10^{\circ}$ boxes in the North Atlantic $\left(\mathrm{Wm}^{-2}\right)$. Horizontal diffusion (black) and vertical diffusion (red) are shown separately. The error bars indicate two standard errors of the seasonal values used to obtain the seasonal mean. 
Table 6. The annual mean heat budget residual, $\left(\mathrm{Wm}^{-2}\right)$ based on (a) NCEP and (b) NOC atmospheric variables. Bold text indicates where closure of the heat budget is obtained to within the quoted error (i.e. residual not significantly different from zero).

\begin{tabular}{lrrrrrrr}
\hline a) & $75-65^{\circ} \mathrm{W}$ & $65-55^{\circ} \mathrm{W}$ & $55-45^{\circ} \mathrm{W}$ & $45-35^{\circ} \mathrm{W}$ & $35-25^{\circ} \mathrm{W}$ & $25-15^{\circ} \mathrm{W}$ & $15-5^{\circ} \mathrm{W}$ \\
\hline $50-60^{\circ} \mathrm{N}$ & - & - & $\mathbf{3 0} \pm \mathbf{5 7}$ & $-\mathbf{2 9} \pm \mathbf{5 5}$ & $-\mathbf{2 9} \pm \mathbf{4 0}$ & $-46 \pm 32$ & - \\
$40-50^{\circ} \mathrm{N}$ & - & - & $206 \pm 136$ & $-148 \pm 55$ & $-47 \pm 32$ & $\mathbf{- 4} \pm \mathbf{1 2}$ & $\mathbf{3} \pm \mathbf{1 8}$ \\
$30-40^{\circ} \mathrm{N}$ & - & $-128 \pm 34$ & $-89 \pm 40$ & $-49 \pm 23$ & $-\mathbf{8} \pm \mathbf{9}$ & $-15 \pm 9$ & - \\
$20-30^{\circ} \mathrm{N}$ & $-40 \pm 20$ & $-\mathbf{1 3} \pm \mathbf{2 2}$ & $-\mathbf{3 2} \pm \mathbf{3 1}$ & $-54 \pm 24$ & $-55 \pm 35$ & $-\mathbf{1 6} \pm \mathbf{3 8}$ & - \\
b) & $75-65^{\circ} \mathrm{W}$ & $65-55^{\circ} \mathrm{W}$ & $55-45^{\circ} \mathrm{W}$ & $45-35^{\circ} \mathrm{W}$ & $35-25^{\circ} \mathrm{W}$ & $25-15^{\circ} \mathrm{W}$ & $15-5^{\circ} \mathrm{W}$ \\
$50-60^{\circ} \mathrm{N}$ & - & - & $\mathbf{4 0} \pm \mathbf{5 7}$ & $-\mathbf{2 6} \pm \mathbf{5 5}$ & $-\mathbf{1 4} \pm \mathbf{4 0}$ & $-\mathbf{2 5} \pm \mathbf{3 2}$ & - \\
$40-50^{\circ} \mathrm{N}$ & - & - & $219 \pm 136$ & $-116 \pm 55$ & $-\mathbf{2 9} \pm \mathbf{3 2}$ & $\mathbf{7} \pm \mathbf{1 2}$ & $20 \pm 18$ \\
$30-40^{\circ} \mathrm{N}$ & - & $-78 \pm 34$ & $-49 \pm 40$ & $-\mathbf{1 7} \pm \mathbf{2 3}$ & $17 \pm 9$ & $\mathbf{0} \pm \mathbf{9}$ & - \\
$20-30^{\circ} \mathrm{N}$ & $\mathbf{7} \pm \mathbf{2 0}$ & $36 \pm 22$ & $\mathbf{1 6} \pm \mathbf{3 1}$ & $-\mathbf{5} \pm \mathbf{2 4}$ & $-\mathbf{4} \pm \mathbf{3 5}$ & $\mathbf{1 2} \pm \mathbf{3 8}$ & \\
\hline
\end{tabular}

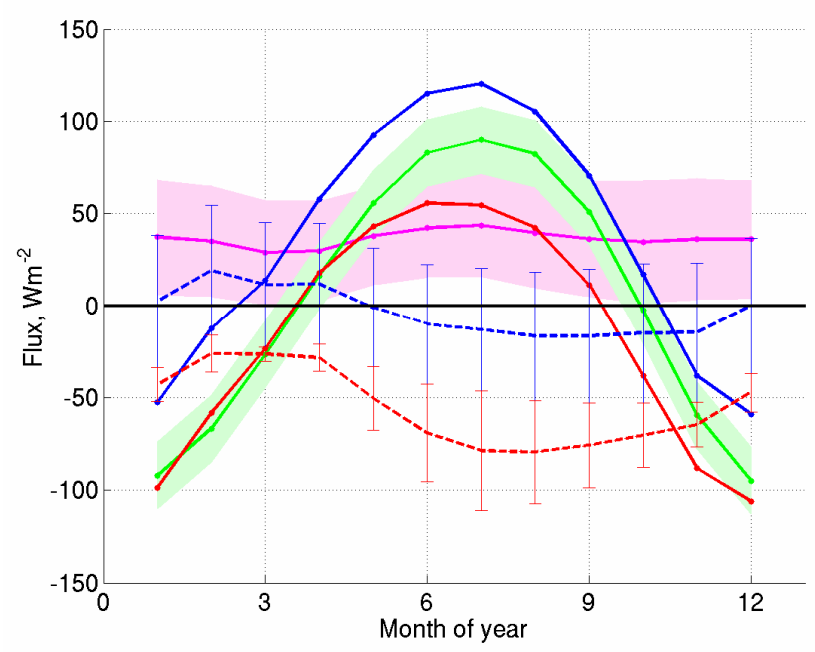

Fig. 9. The seasonal cycle in the heat budget components at 20 $30^{\circ} \mathrm{N}, 35-25^{\circ} \mathrm{W}$. The NCEP net heat flux (red), NOC net heat flux (blue), heat storage (green), heat convergence (pink), the NCEP heat budget residual (red dashed) and the NOC heat budget residual (blue dashed) are shown. Shading indicates estimated errors for each term.

mean heat divergence from diffusion, and the seasonal cycle, respectively. The annual mean values range from 4 to $76 \mathrm{Wm}^{-2}$ with the largest values at $30^{\circ}-40^{\circ} \mathrm{N}, 45^{\circ}-55^{\circ} \mathrm{W}$ (East of Newfoundland). These calculated values are based on a horizontal coefficient typical of the North Atlantic at this scale in the upper $100 \mathrm{~m}$, but the uncertainty of this coefficient is high close to the Gulf Stream extension region and consequently the estimated errors are large. The errors in the diffusion term are difficult to estimate and are assumed to be $100 \%$ of the calculated value. With this assumption, the errors are greatest in the Gulf Stream where both horizontal and vertical diffusion terms make a significant contribution to the heat budget. The smallest contribution is in the eastern subtropical Atlantic where the horizontal temperature gradients are weakest.

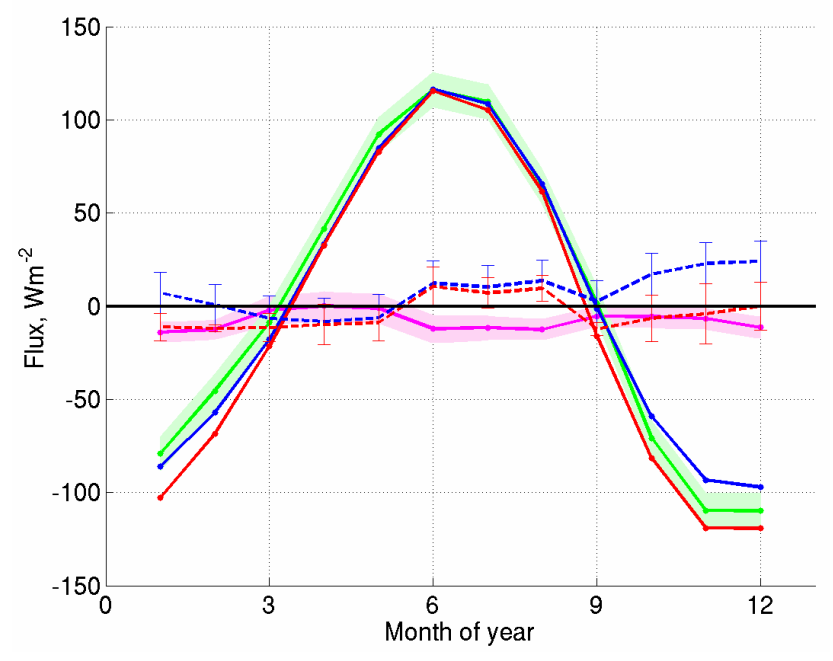

Fig. 10. The seasonal cycle in the heat budget components at 40$50^{\circ} \mathrm{N}, 25-15^{\circ} \mathrm{W}$. The NCEP net heat flux (red), NOC net heat flux (blue), heat storage (green), heat convergence (pink), the NCEP heat budget residual (red dashed) and the NOC heat budget residual (blue dashed) are shown. Shading indicates estimated errors for each term.

We have combined the individual sources of error discussed above, assuming that they are independent, to give an overall estimate of error in the residual heat budget shown in Table 6 and this will be discussed in the next section.

\subsection{Closing the heat budget}

We now consider the extent to which the heat budget can be closed for individual $10^{\circ} \times 10^{\circ}$ boxes in the North Atlantic. The residual $(R)$ is defined to be sum of the individual terms in Eq. (1). (i.e. $R=$ Surface Flux - Change in Heat Storage Advection - Diffusion). A positive value of the Residual indicates the heat budget has an excess of heat into the ocean. When $R$ is less than the overall estimated error the heat budget is said to be closed. The residual therefore provides a 


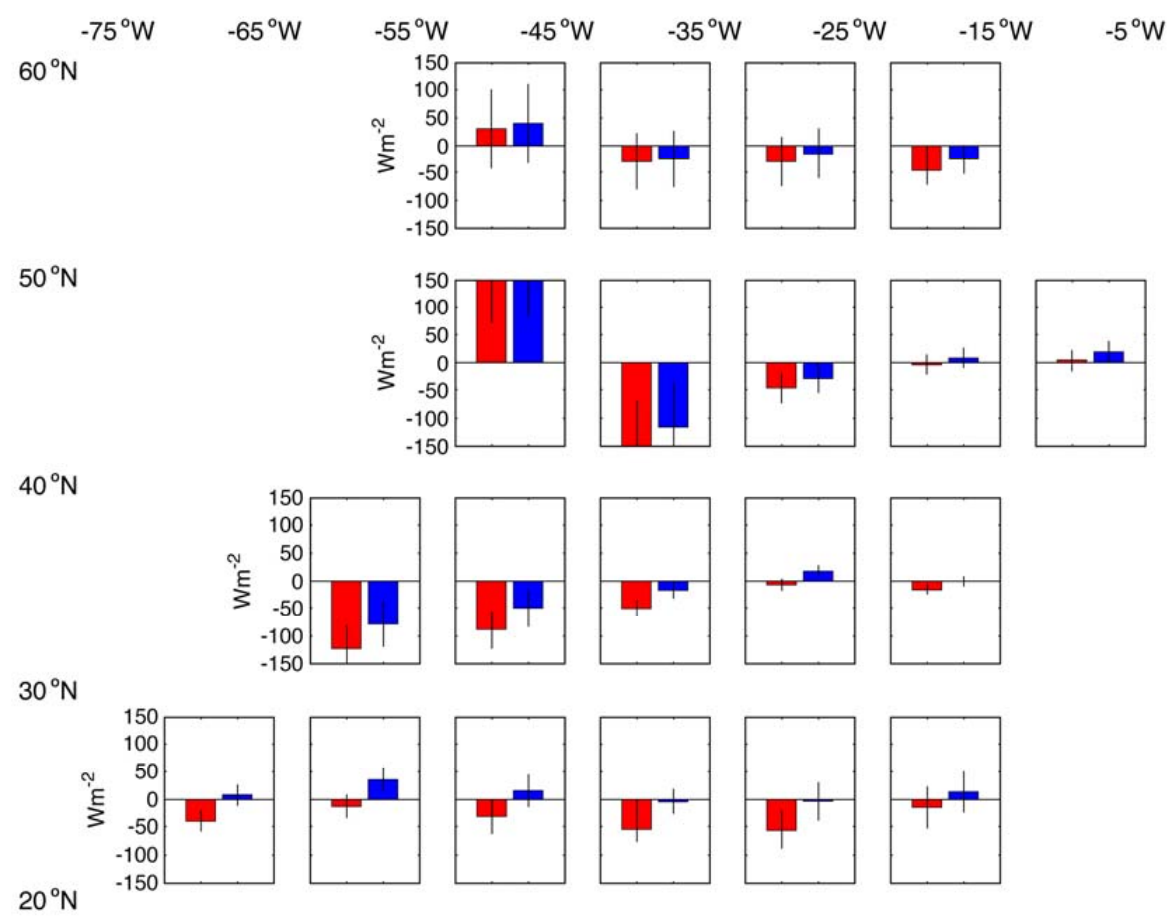

Fig. 11. Graphical representation of residual heat flux (see text for details). NCEP-based heat budget residual in red, NOC-based values in blue.

measure of the closure of heat budget using either the NCEP or the NOC fluxes. First, the seasonal heat budget for two specific boxes will be presented, followed by a more the general discussion of the residuals for all of the boxes in the $20^{\circ}-$ $60^{\circ} \mathrm{N}$ latitude range.

Figure 9 shows the components of the heat budget for a box at $20-30^{\circ} \mathrm{N}, 35-25^{\circ} \mathrm{W}$, in the subtropical Atlantic Ocean, where the residual heat flux is small. The budget has been determined for surface heat fluxes from NCEP (red) and NOC (blue). The correspondence between the heat storage (green) and the surface fluxes is reasonably good. The heat storage lies within the envelope of NOC and NCEP, and whilst the agreement is better with NCEP in the early half of year, with NCEP it is poorer in late summer and autumn. The residual of the heat budget shows that over the year the use of the NOC flux brings the budget closer to zero than when NCEP is used. The NCEP budget has an annual mean residual of $-55 \pm 35 \mathrm{Wm}^{-2}$ compared with a NOC value of $-4 \pm 35 \mathrm{Wm}^{-2}$. At this box we find that the net heat divergence of $36 \mathrm{Wm}^{-2}\left(\right.$ Ekman $=-4 \mathrm{Wm}^{-2}$, geostrophic $=11 \mathrm{Wm}^{-2}$, diffusion $=29 \mathrm{Wm}^{-2}$ ) offsets the net heating from the NOC surface heat fluxes.

A second example of the heat budget is given at $40^{\circ}-$ $50^{\circ} \mathrm{N}, 25^{\circ}-15^{\circ} \mathrm{W}$ (Fig. 10). The heat budget for this box is dominated by surface heat flux and heat storage and heat convergence makes only a small contribution. The residual is less than the error estimate for both NCEP $\left(-4 \pm 12 \mathrm{Wm}^{-2}\right)$ and NOC $\left(+7 \pm 12 \mathrm{Wm}^{-2}\right)$ and therefore confirms the closure for this box to this accuracy. However, we cannot distinguish any difference in residual when NCEP and NOC net surface fluxes are used in the heat budget.

The values of the residuals for all of the individual boxes are shown in Fig. 11 and Table 6. For the latitude band $20^{\circ}$ $30^{\circ} \mathrm{N}$, the NOC fluxes produce closure in 5 of the 6 boxes, whilst for NCEP fluxes closure is found in 3 of the 6 boxes. In the latitude band $30^{\circ}-40^{\circ} \mathrm{N}$ there is closure in only one NCEP box, whilst NOC has closure in 2 of the 5 boxes. Further north, for $40^{\circ}-50^{\circ} \mathrm{N}$ closure is obtained for 2 boxes using NCEP and NOC. Finally, at $50^{\circ}-60^{\circ} \mathrm{N}$ we have closure of all 4 of the NOC boxes and 3 of the NCEP boxes. Over the whole range $20^{\circ}-60^{\circ} \mathrm{N}$, closure is obtained for 13 (9) out of 20 boxes with NOC (NCEP) surface fluxes.

\section{Summary and conclusion}

An analysis of the heat budget of the upper ocean (0-300 m) for the North Atlantic from $20^{\circ}-60^{\circ} \mathrm{N}$ based on Argo profiling floats and surface flux fields from NCEP/NCAR and NOC has been presented. Individual terms in the budget have been assessed for $10^{\circ} \times 10^{\circ}$ boxes in the North Atlantic and closure of the heat budget is obtained within the error estimates for some regions but not for those boxes that include 
the Gulf Stream. For NCEP, 9 out of 20 boxes, and for NOC, 13 out of 20 boxes meet the criterion of closure within the estimated error.

The lowest error estimates for the net heat budget $\left( \pm 9 \mathrm{Wm}^{2}\right)$ are in the eastern and central subtropical gyre for two boxes $35^{\circ}-25^{\circ} \mathrm{W}$ and $25^{\circ}-15^{\circ} \mathrm{W}$ between $30^{\circ}$ and $40^{\circ} \mathrm{N}$.

The analysis of the $35^{\circ}-25^{\circ} \mathrm{W}$ box has shown that closure of the heat budget can be obtained with both NCEP and NOC surface fluxes. Further south, a detailed seasonal heat budget for the box $\left(20^{\circ}-30^{\circ} \mathrm{N}, 35^{\circ}-25^{\circ} \mathrm{W}\right)$ reveals a large residual in the heat budget when NCEP is used $-55 \pm 35 \mathrm{Wm}^{-2}$ whilst when NOC fluxes are applied the residual is small $-4 \pm 35 \mathrm{Wm}^{-2}$. This is consistent with an earlier evaluation of the NOC and NCEP/NCAR fluxes using measurements from research buoys in the subduction array (Moyer and Weller, 1997; Josey 2001) which revealed biases in NCEP but good agreement of the buoy values with the NOC fields (Josey, 2001). It is noted error estimates in the sub-polar gyre are $\pm 30-60 \mathrm{Wm}^{-2}$ are a little lower than those quoted by Gulev (2007).

To conclude, closure of the heat budget using Argo data combined with surface flux fields has been obtained for $65 \%$ of the $10^{\circ} \times 10^{\circ}$ boxes considered in the North Atlantic when NOC surface heat fluxes have been used and $45 \%$ when NCEP fluxes are used. Significant problems remain at present towards the western boundary region including the Gulf Stream where closure has not been achieved. Our analysis has only considered Argo data up to the end of 2005 and the region $20^{\circ}-60^{\circ} \mathrm{N}$. As the time period covered by Argo and number of floats increases, we anticipate being able to obtain a better understanding of the processes controlling the heat budget over a greater region of the North Atlantic and other basins.

Acknowledgements. Rachel Hadfield's studentship was provided by the NERC RAPID programme.

These data were collected and made freely available by the International Argo Project and the national programs that contribute to it (http://wo.jcommops.org/).

Argo is a pilot program of the Global Ocean Observing System.

Edited by: A. Sterl

\section{References}

Alderson, S. G. and Killworth, P. D.: A preoperational scheme for calculating sea surface height by Bernoulli inverse of Argo float data in the North Atlantic, J. Atmos. Ocean. Tech., 22(9) 14161422, 2005.

Böhme, L. and Send, U.: Objective analyses of hydrographic data for referencing profiling float salinities in highly variable environments, Deep Sea Res. II, 52(3-4), 651-664, 2005.
Böning, C. W. and Herrmann, P.:Annual cycle of poleward heat transport in the ocean: Results from high resolution modelling of the North and Equatorial Atlantic, J. Phys. Oceanogr., 24, 91107, 1994.

Bretherton, F. P., Davis, R. E., and Fandry, C. B.: A technique for objective analysis and design of oceanographic experiments applies to MODE-73, Deep-Sea Res., 23, 559-582, 1976.

Bryden, H. L. and Imawaki, S.: Ocean heat transport, 455-474, in: Ocean Circulation and Climate, edited by: Seidler, G., Church, J., and Gould, J., Academic Press, 715 pp., 2001.

Cunningham, S. A.: Circulation and volume flux of the North Atlantic using synoptic hydrographic data in a Bernoulli inverse, J. Mar. Res., 58(1), 1-35, 2000.

Dong, S. and Kelly, K. A.: Heat Budget in the Gulf Stream Region: The Importance of Heat Storage and Advection, J. Phys. Oceanogr., 34, 1214-1231, 2003.

Gandin, L. S.: Objective Analysis of Meteorological Fields, Leningrad, Gidrometeorol Izdat, 242 pp., 1963.

Gill, A. E. and Niiler, P. P.: The theory of seasonal variability in the ocean, Deep Sea Res., 20, 141-177, 1973.

Gould, W. J.: From Swallow floats to Argo-the development of neutrally buoyant floats, Deep Sea Res. II, 52, 529-543, 2005.

Grist, J. P. and Josey, S. A.: Inverse Analysis of the SOC Air-Sea Flux Climatology Using Ocean Heat Transport Constraints, J. Climate, 16(20), 3274-3295, 2003.

Gulev, S. K., Jung, T., and Ruprecht, E.: Estimation of the impact of sampling errors in the VOS observations on air-sea fluxes. Part I. Uncertainties in climate means, J. Climate, 20, 279-301, 2007.

Hadfield, R. E., Wells, N. C., Josey, S. A., Hirschi, J. J.M.: On the accuracy of North Atlantic temperature and heat storage fields from Argo, J. Geophys. Res., 112, C01009, doi:10.1029/2006JC003825, 2007a.

Hadfield, R. E.: The North Atlantic Study: An Argo Based Study, $\mathrm{PhD}$ thesis, University of Southampton, 198 pp., $2007 \mathrm{~b}$.

Jones, I. and Leach, H.: Isopycnic Modeling of the North Atlantic Heat Budget, J. Geophys. Res., 104, 1377-1392, 1999.

Josey, S. A., Kent, E. C., and Taylor, P. K.: The Southampton Oceanography Centre (SOC) ocean-atmosphere heat, momentum, and freshwater flux atlas, National Oceanography Centre, Southampton report 6, Southampton, UK, 30 pp., 1998.

Josey, S. A., Kent, E. C., and Taylor, P. K.: New Insights into the Ocean Heat Budget Closure Problem from Analysis of the SOC Air-Sea Flux Climatology, J. Climate, 12(9), 2856-2880, 1999.

Josey, S. A.: A comparison of ECMWF, NCEP-NCAR and SOC surface fluxes with moored buoy measurements in the subduction region of the Northeast Atlantic, J. Climate, 14, 1780-1789, 2001.

Kalnay, E., Kanamitsu, M., Kistler, R., et al.: The NCEP/NCAR 40 year reanalysis project, B. Am. Meteorol. Soc., 77, 437-471, 1996.

Kistler, R., Kalnay, E., Kalnay, E., Collins, W., et al.: The NCEP/NCAR 50 year reanalysis project: Monthly means and CD-ROM and documentation, B. Am. Meteorol. Soc., 82(2), 247-267, 2001.

Lamb, P. J. and Bunker, A. F.: The annual march of the heat budget of the North and Tropical Atlantic Oceans, J. Phys. Oceanogr., 12, 1388-1410, 1982.

Ledwell, J. R.,Watson, A. J., and Law, C. S.: Evidence for slow mixing across the pycnocline from an open-ocean tracer release 
experiment, Nature, 364, 6439, 701-703, 1993.

McCulloch, M. E. and Leach, H.: Air-sea fluxes inferred from an upper ocean heat budget north east of the Azores, Q. J. Roy. Meteor. Soc., 124, 2465-2476, 1998.

Montegut, C. D., Madec, G., Fischer, A. S., et al.: Mixed layer depth over the global ocean: an examination of profile data and profile based climatology, J. Geophys. Res., 109, C12003, doi:10.1029/2004JC002378, 2004.

Moyer, K. A. and Weller, R. A.: Observations of surface forcing from the Subduction Experiment: A comparison with global model products and climatological data sets, J. Climate, 10, 2725-2742, 1997.

Renfrew, I. A., Guest, P. S., and Bumke, K.: A comparison of surface layer and surface turbulent flux observations over the Labrador Sea with ECMWF analyses and NCEP analyses, J. Phys. Oceanogr., 32, 383-400, 2002.

Sarmiento, J. L.: On the North and Tropical Atlantic Heat Balance, J. Geophys. Res., 91, 11677-11689, 1986.
Schafer, H. and Kraus, W.: Eddy statistics in the South Atlantic as derived from drifters drogued at $100 \mathrm{~m}$, J. Mar. Res., 53, 403431, 1995.

Stammer, D., Ueyoshi, K., Köhl, A., Large, W. G., Josey, S. A., and Wunsch, C.: Estimating air-sea fluxes of heat, freshwater, and momentum through global ocean data assimilation, J. Geophys. Res., 109, C05023, doi:10.1029/2003JC002082, 2004.

Stephens, C., Antonov, J. I., Boyer, T. P., Conkright, M. E., Locarnini, R. A., O'Brien, T. D., Garcia, H. E., and Levitus, S.: World Ocean Atlas 2001, Vol. 1: temperature, NOAA atlas NESDIS 49, 176 pp., 2001.

Stevenson, J. W. and Niiler, P. P.: Upper ocean heat budget during the Hawaii-to-Tahiti Shuttle Experiment, J. Phys. Oceanogr., 13, 1895-1907, 1983.

Webb, D. J., de Cuevas, B. A., and Coward, A. C.: The first main run of the OCCAM global ocean model, Internal document 34, Southampton Oceanography Centre, UK, 44 pp., 1998.

Wang, J. and Carton, J. A.: Seasonal heat budgets of the North Pacific and North Atlantic Oceans, J. Phys. Oceanogr., 32, 3474 3489, 2002. 